\title{
Assessment of the Possibility to Measure Deformations of Rock Walls Using Terrestrial Laser Scanning**
}

\section{Introduction}

Unexpected rockfalls and rock displacements belong to most significant dangers related to slope engineering. It may cause not only serious changes in the environment but also, and most of all, danger for infrastructure and can even lead to fatal accidents. Therefore, ensuring security in both open-pit mining and on the rocky slopes in the area of road cuts requires instant monitoring of the stability and displacements of slopes and determining the dynamics of emerging changes [1-3]. Data concerning rock mechanics provided by the measurements enable undertaking proper actions in order to predict the development of movement and start preventive and protective works [4]. Currently, the most often used methods of measuring rock geometry are direct methods (total station). On the other hand, in order to define additional slope parameters, specialized measuring systems (extensometer, inclinometer) are used. Using classic surveying instruments imposes considerable limitations caused by the necessity to generalization and interpolation of obtained measurement results. The same applies to slope stress and strain measurements. Dynamic development of surveying technologies including Terrestrial Laser Scanning (TLS) allows for fast retrieval of measurement data. The additional advantage of TLS is its ability to quickly obtain data of very high resolution and accuracy without direct contact with the examined object. Thus, it allows for the carrying out measurements for the whole object without the need for generalization. It offers new possibilities for analysis and interpretation of obtained results [5, 6].

This paper presents the possibilities of using TLS method for marking displacements and volume of rock cavities formed as a result of natural and anthropogenic weathering. Discussed works are supported by exemplary measurements conducted in the area of abandoned limestone quarry "Zakrzówek" in Cracow.

* AGH University of Science and Technology, Faculty of Mining Surveying and Environmental Engineering, Krakow, Poland

** The paper was prepared within the scope of the Dean Project of the Faculty of Mining Surveying and Environmental Engineering (AGH University of Science and Technology) no. 15.11.150.388. 


\section{The Object of the Study}

Three rock walls were selected for this study. The first of them was recognized as a laboratory case due to its solid structure and low susceptibility to weathering. Its geological structure is very similar to the others. Thus, it was used to determine the accuracy and reproducibility of performed studies. The other two objects are subject to natural weathering (freeze-thaw and biogeochemical weathering) and intensive anthropogenic weathering.

Due to numerous climbing lines situated on the rock walls, periodic cleaning of the fragments of loosely-connected rocks has to be held in order to ensure security of the climbers. Such works have been completed between first and second measurement series.

\section{Field Measurements}

The first step of field works was to create and measure the control network. Its main task is to preserve the maximum measurement reproducibility between successive measuring sessions. Network points were mounted in a way that allows for the minimization of point cloud registration error. Four permanent ground control points, equally distributed on measuring objects, were fixed for this purpose. Fifteen centimeter long threaded studs, glued inside the holes drilled in the solid rock fragments, were used for mounting. This way, forced centering points for circular planar target Leica HDS 6 were established.

During the first measuring session (4 February 2014) network points were measured by reflectorless total station Leica TCRA 1102plus and additionally a static GNSS measurement with two Leica GPS1200 receivers was performed for georeferencing in a state system. Additionally, in order to control the stability of control points, tacheometry measurements of the network geometry were carried out during each measurement session.

A key step of field works was related to TLS measurements carried out in four measuring sessions (4 February 2014, 14 March 2014, 7 November 2014, 15 March 2015). TLS measurement was performed by time-of-flight scanner Leica ScanStation C10. Scans of particular objects were taken from one station with the resolution of $5 \times 5 \mathrm{~mm}$ on the maximum distance to the measured object, however, distances for particular objects ranged between 20-50 m. Tests regarding different distances between the scanner and the object were not performed. It was considered that the previously mentioned range is sufficient for examining deformations of objects of this type in the majority of cases.

All the measurements were conducted in similar weather conditions at temperatures ranging from $5^{\circ} \mathrm{C}$ to $10^{\circ} \mathrm{C}$ without any rainfall and the examined objects were dry. 


\section{The Study of Measurement Data}

The first step of processing was to determine the coordinates of the network. The least square parametric adjustment of tacheometry and GNSS observation was made in C-GEO software. The absolute root mean square error of point position at the level of $4 \mathrm{~mm}$ in the Polish State Coordinate System PL-2000 was obtained as a result of the calculations.

Simultaneously, due to installing the ground control points on the examined object, it was very significant to check its relative stability between subsequent measuring sessions. Therefore, after each session the least square isometric transformation of coordinates obtained from tacheometric measurement and scanning the initial coordinates of the network was conducted in order to detect prospective relative displacements of the network. Considering the character of the object, the analysis was conducted in object local coordinate system. It allowed for avoidance of the impact of distortion and errors connected with tying measurements to state coordinate system on the results. Obtained differences are presented in Table 1.

Table 1. Testing the stability of control points

\begin{tabular}{|c|c|c|c|c|c|c|c|c|c|c|c|c|c|}
\hline \multirow[b]{2}{*}{ Session } & \multirow{2}{*}{$\begin{array}{l}\text { Tar- } \\
\text { get } \\
\text { ID }\end{array}$} & \multicolumn{4}{|c|}{ Total station } & \multicolumn{4}{|c|}{ TLS } & \multicolumn{4}{|c|}{ TLS (after reduction) } \\
\hline & & $\begin{array}{c}v X \\
{[\mathrm{~mm}]}\end{array}$ & $\begin{array}{c}v Y \\
{[\mathrm{~mm}]}\end{array}$ & $\begin{array}{c}v H \\
{[\mathrm{~mm}]}\end{array}$ & $\begin{array}{c}m P \\
{[\mathrm{~mm}]}\end{array}$ & $\begin{array}{c}v X \\
{[\mathrm{~mm}]}\end{array}$ & $\begin{array}{c}v Y \\
{[\mathrm{~mm}]}\end{array}$ & $\begin{array}{c}v H \\
{[\mathrm{~mm}]}\end{array}$ & $\begin{array}{c}m P \\
{[\mathrm{~mm}]}\end{array}$ & $\begin{array}{c}v X \\
{[\mathrm{~mm}]}\end{array}$ & $\begin{array}{c}v Y \\
{[\mathrm{~mm}]}\end{array}$ & $\begin{array}{c}v H \\
{[\mathrm{~mm}]}\end{array}$ & $\begin{array}{c}m P \\
{[\mathrm{~mm}]}\end{array}$ \\
\hline \multirow{4}{*}{1} & 201 & - & - & - & - & -3 & -3 & 2 & 5 & 1 & 1 & 2 & 3 \\
\hline & 202 & - & - & - & - & -1 & 4 & 2 & 4 & 0 & 0 & -2 & 2 \\
\hline & 203 & - & - & - & - & -2 & -2 & 0 & 3 & -1 & -1 & -1 & 1 \\
\hline & 204 & - & - & - & - & 6 & 2 & -4 & 7 & 0 & 0 & 0 & 0 \\
\hline \multirow{4}{*}{2} & 201 & -2 & -2 & 1 & 3 & -4 & -5 & 2 & 6 & -1 & 0 & 2 & 2 \\
\hline & 202 & -1 & 2 & 1 & 2 & -1 & 4 & 3 & 5 & 0 & -1 & -1 & 1 \\
\hline & 203 & 0 & 0 & 0 & 0 & -3 & -2 & -1 & 3 & -1 & -1 & -2 & 2 \\
\hline & 204 & 2 & 1 & -2 & 3 & 7 & 3 & -4 & 9 & 2 & 1 & 0 & 2 \\
\hline \multirow{4}{*}{3} & 201 & -2 & -5 & -2 & 6 & -3 & -5 & -3 & 6 & 1 & -1 & -2 & 2 \\
\hline & 202 & -2 & 3 & 2 & 4 & 0 & 5 & 5 & 7 & 1 & 1 & 2 & 2 \\
\hline & 203 & 1 & 3 & 1 & 3 & -2 & 0 & 2 & 3 & 0 & 1 & 1 & 2 \\
\hline & 204 & 3 & -1 & -1 & 3 & 4 & 0 & -4 & 6 & -1 & -2 & -1 & 2 \\
\hline \multirow{4}{*}{4} & 201 & 0 & -1 & -3 & 3 & -4 & -5 & -3 & 7 & -1 & 0 & -3 & 3 \\
\hline & 202 & -1 & 2 & 3 & 3 & -1 & 5 & 4 & 6 & 0 & 0 & 1 & 1 \\
\hline & 203 & 1 & -1 & 1 & 1 & -1 & -1 & 2 & 2 & 1 & 0 & 1 & 2 \\
\hline & 204 & 1 & 0 & 0 & 1 & 5 & 2 & -3 & 6 & -1 & 0 & 1 & 1 \\
\hline & & & \multicolumn{2}{|c|}{ Average } & 3 & & \multicolumn{2}{|c|}{ Average } & 5 & & \multicolumn{2}{|c|}{ Average } & 2 \\
\hline & & & \multicolumn{2}{|c|}{$\begin{array}{c}\text { Std. } \\
\text { deviation }\end{array}$} & 1 & & \multicolumn{2}{|c|}{$\begin{array}{c}\text { Std. } \\
\text { deviation }\end{array}$} & 2 & & \multicolumn{2}{|c|}{$\begin{array}{c}\text { Std. } \\
\text { deviation }\end{array}$} & 1 \\
\hline
\end{tabular}


The results obtained by comparing tacheometric measurements from all sessions allow for the conclusion that the network was constant during the measurement. The average value of coordinate differences did not exceed $3 \mathrm{~mm}$. Taking into consideration surveying equipment that was used, this value has to be regarded as measurement error. Analysing the results obtained from comparison of scanning and tacheometric measurement results, systematic error in a laser scanner can be noted. The corrections on particular points take similar values for subsequent measurement sessions. It may indicate instrumental errors in a laser scanner. After eliminating the systematic errors, the results of coordinate differences reached less than $3 \mathrm{~mm}$, which shows high reproducibility of scanning measurement. Additional conclusion that derives from this analysis is that the examination of control points stability can be successfully performed with the use of a laser scanner. It should be noted that the instrument used for this purpose has to be fully calibrated. After establishing the constancy of control points, it was possible to conduct transformation of the whole point clouds to the homogenous coordinate system. In order to do that, the registration of point clouds into the coordinates from least square adjustment was performed in Leica Cyclone 7.3. Mean registration error ranged from 2 to $4 \mathrm{~mm}$ depending on measurement session.

\section{Methods of Comparing Point Clouds and Their Accuracy}

Point cloud is characterized by very high density. However, it has to be noted that the reconstruction of exact localization of individual points from subsequent measurement sessions is almost impossible. Direct comparison and determination of deformation value of the examined object is therefore impossible [7]. Thus, it is necessary to run the analysis of the entire set of points for data provided by the laser scanner. Analyses of this type can be carried out in various ways. The first method that is presented involves the comparison of two point clouds and examining the distance between them, it is so called Cloud to Cloud method (C2C). The second approach is based on comparing TIN models (Triangulated Irregular Network) formed from point clouds for the examined measurement sessions [8].

TIN model comparison method is most frequently used. Thanks to the use of Triangular Irregular Network deformation values are measured alongside the normals for particular triangles, which enable determining the sign of deformation and gives reasonably accurate and realistic results. Simultaneously, this method allows for the determination of deformations in the objects with irregular structure and is independent from point cloud density variable. Inaccuracies caused by inadequate filtering of source point clouds emerging while creating a model may create problems. Even individual outliers may negatively influence the accuracy of the study. It results in a false image of deformation in which it is impossible to indicate incorrect point, which inhibits further study of the results. What is more, all analytical processes require substantial memory resources and processing power of a computer, especially with larger databases. 
Another approach to examine object displacements are the analyses based on comparing raw data, i.e. $\mathrm{C} 2 \mathrm{C}$ method. They are based on approximating the distance from the compared cloud to local modeling reference cloud surface.

The biggest advantages of $\mathrm{C} 2 \mathrm{C}$ methods are listed below:

- direct operating on the set of points provides the values of deformation for particular points,

- they require far less processing power, comparing to the methods based on TIN,

- they are more resistant to the occurrence of outliers.

Among $\mathrm{C} 2 \mathrm{C}$ methods, the following types of reference point cloud modeling can be distinguished: Nearest Neighbor, Least Square Plane, Height Function, 2.5D Delaunay Triangulation and Multiscale Model to Model Cloud Comparison (M3C2) $[8,9]$. Particular methods are characterized by different approach towards calculating the values of distances between the point clouds.

In order to assess the accuracy and effectiveness of particular methods, the analysis of laboratory case object was conducted. The comparison of point clouds was performed with the use of CloudCompare v2.6.1 program for which the radius of local modeling was defined as $10 \mathrm{~cm}$ for all methods. This value allowed the best preservation of irregular structure of the object. On the other hand, the comparison of TIN models was performed in Geomagic Studio 12 program. Detailed results (differences between clouds of the third and fourth series) obtained for respective methods are presented in Table 2 .

Table 2. Result of point clouds comparison (third and fourth session)

\begin{tabular}{|c|c|c|c|c|c|c|c|c|c|c|c|c|c|c|c|}
\hline \multirow[b]{2}{*}{ Method } & \multicolumn{3}{|c|}{ Original $(5 \mathrm{~mm})$} & \multicolumn{3}{|c|}{$10 \mathrm{~mm}$} & \multicolumn{3}{|c|}{$25 \mathrm{~mm}$} & \multicolumn{3}{|c|}{$50 \mathrm{~mm}$} & \multicolumn{3}{|c|}{$100 \mathrm{~mm}$} \\
\hline & $\begin{array}{c}\text { avg. } \\
{[\mathrm{mm}]}\end{array}$ & $\begin{array}{l}\text { std. } \\
\text { dev. } \\
{[\mathrm{mm}]}\end{array}$ & $<99 \%$ & $\begin{array}{l}\text { avg. } \\
{[\mathrm{mm}]}\end{array}$ & $\begin{array}{l}\text { std. } \\
\text { dev. } \\
{[\mathrm{mm}]}\end{array}$ & $<99 \%$ & $\begin{array}{l}\text { avg. } \\
{[\mathrm{mm}]}\end{array}$ & $\begin{array}{l}\text { std. } \\
\text { dev. } \\
{[\mathrm{mm}]}\end{array}$ & $<99 \%$ & $\begin{array}{l}\text { avg. } \\
{[\mathrm{mm}]}\end{array}$ & {$\left[\begin{array}{c}\text { std. } \\
\text { dev. } \\
{[\mathrm{mm}]}\end{array}\right]$} & $<99 \%$ & $\begin{array}{c}\text { avg. } \\
{[\mathrm{mm}]}\end{array}$ & $\begin{array}{l}\text { std. } \\
\text { dev. } \\
{[\mathrm{mm}]}\end{array}$ & $<99 \%$ \\
\hline $\begin{array}{l}\text { Nearest } \\
\text { Neighbor }\end{array}$ & 5 & \pm 2 & 11 & 6 & \pm 3 & 13 & 11 & \pm 4 & 21 & 17 & \pm 7 & 33 & 21 & \pm 13 & 59 \\
\hline $\begin{array}{l}\text { Least Square } \\
\text { Plane }\end{array}$ & 3 & \pm 2 & 9 & 4 & \pm 3 & 11 & 5 & \pm 4 & 16 & 6 & \pm 5 & 24 & 8 & \pm 8 & 42 \\
\hline $\begin{array}{l}\text { Height } \\
\text { Function }\end{array}$ & 3 & \pm 2 & 10 & 3 & \pm 3 & 11 & 5 & \pm 4 & 16 & 6 & \pm 6 & 25 & 20 & \pm 13 & 59 \\
\hline $\begin{array}{l}\text { 2.5D Trian- } \\
\text { gulation }\end{array}$ & 2 & \pm 2 & 8 & 2 & \pm 2 & 9 & 3 & \pm 3 & 12 & 4 & \pm 4 & 19 & 10 & \pm 11 & 52 \\
\hline M3C2 & -1 & \pm 1 & $-3 / 3$ & 0 & \pm 2 & $-4 / 4$ & 0 & \pm 2 & $-5 / 8$ & 0 & \pm 3 & $-6 / 9$ & 0 & \pm 3 & $-8 / 9$ \\
\hline TIN Models & & da & & 0 & \pm 7 & - & 0 & \pm 7 & - & 0 & \pm 5 & - & -1 & \pm 8 & - \\
\hline
\end{tabular}


Laboratory case object is characterized by solid structure; therefore, it was assumed that expected compared values should be close to zero. Figure 1 shows the results obtained from different methods of comparing point clouds with maximum density $(5 \mathrm{~mm})$, which are presented for the fragment of test object.

This is the area of the maximum variety of structure, and thereby it determines the biggest errors of the comparison. Despite the figures which show the image of the test object, the graphs showing the differences of distances between point clouds displayed by the amounts of points in a given range of differences were presented.

Applying the Nearest Neighbor method, the mean distance between point clouds reached the level of $5 \mathrm{~mm}$ with the standard deviation of $\pm 2 \mathrm{~mm}$. This result is based on point cloud density which was $5 \mathrm{~mm}$. The greatest differences between point clouds appeared in rock depressions, where the differences between point clouds reached even up to $30 \mathrm{~mm}$. Better results were obtained using the Least Square Plane and Height Function method for which the difference between point clouds amounted for $3 \mathrm{~mm}$ with its error value at $\pm 2 \mathrm{~mm}$. Similarly as in the case of the Nearest Neighbor method, it is noticeable that the biggest depressions of the objects are the places where the greatest errors with values over $10 \mathrm{~mm}$ appear. The 2.5D Triangulation method provided much better results with the difference between the point clouds on the level of $2 \mathrm{~mm}$ determined with the error of $\pm 2 \mathrm{~mm}$. What is more, this method enabled proper interpretation of rock depressions with irregular structure. However, noises and outliers are highly noticeable, which is visible as lighter points with the values up to $5 \mathrm{~mm}$. As it was anticipated, the best results at the level of $0 \pm 1 \mathrm{~mm}$ were obtained with the use of the M3C2 method, which entirely eliminated the influence of noises. The errors in the biggest depressions reaching $5 \mathrm{~mm}$ are most likely caused by unequal covering of the object during subsequent measuring sessions. According to the authors, those errors should be regarded as random errors.

It was impossible to perform a TIN model comparison for original point clouds and available processing power. Therefore, a TIN comparison was initiated by filtering primary point clouds up to $10 \mathrm{~mm}$ resolution. As in the $2.5 \mathrm{D}$ Triangulation method, errors and noises were not eliminated which results in single points of outlier values. On the basis of this analysis, it was stated that the most suitable method for examining deformations of such objects is the M3C2 method.

Next step of the analysis was to determine the optimum resolution which allows the fastest field measurements and ensures the accuracy essential for examining cavities on objects of this type. The analyses were conducted for five cloud densities: original (ca. $5 \mathrm{~mm}$ ), $10 \mathrm{~mm}, 25 \mathrm{~mm}, 50 \mathrm{~mm}$ and $100 \mathrm{~mm}$. Taking into consideration the fact that scanning measurement was performed in GRID network, a similar method in GeoMagic program was adopted for unifying the point clouds.

Figure 2 shows the comparison of point clouds with different density performed by using the M3C2 method. Irregular structure of the clouds with density up to $25 \mathrm{~mm}$ is clearly reflected and significant disturbances are not visible while calculating the differences. 
a)
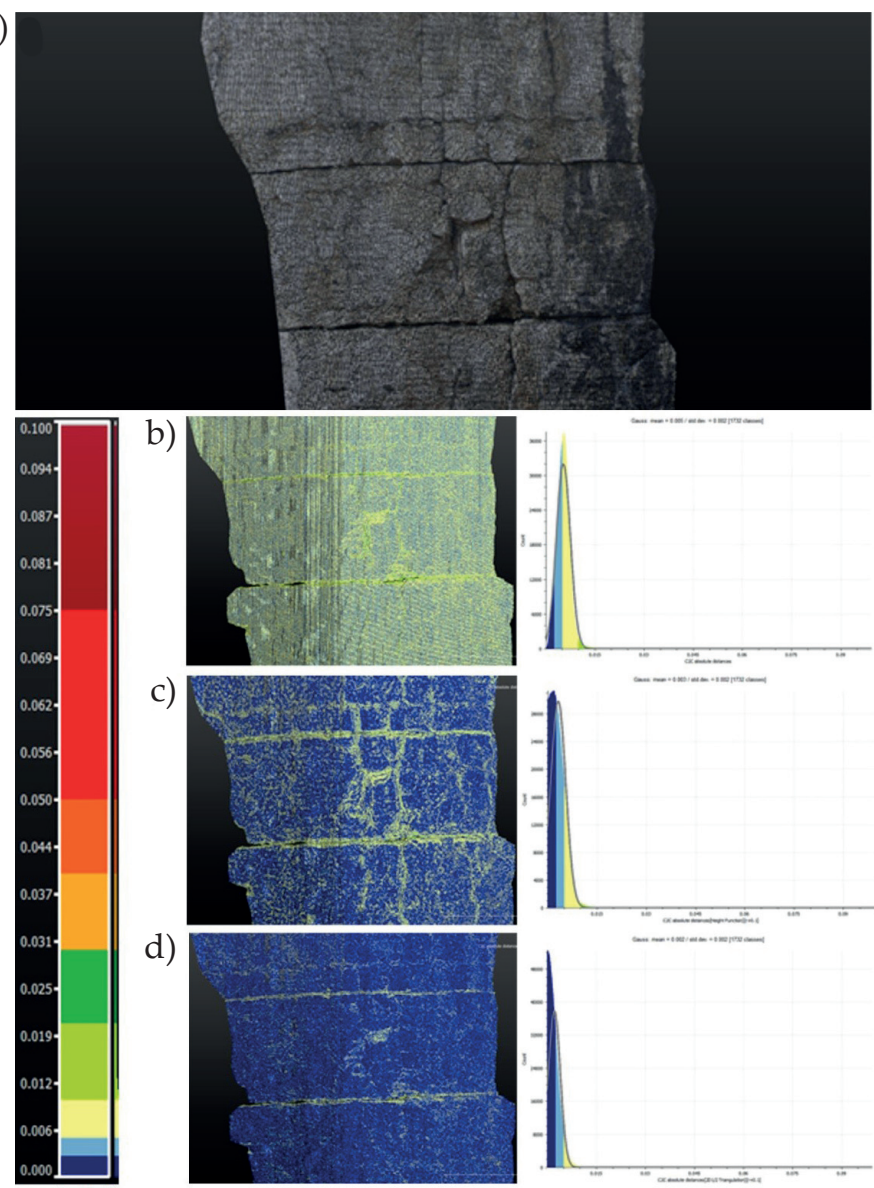

b)

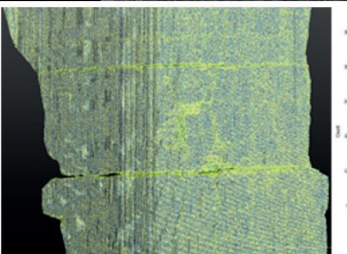

c)
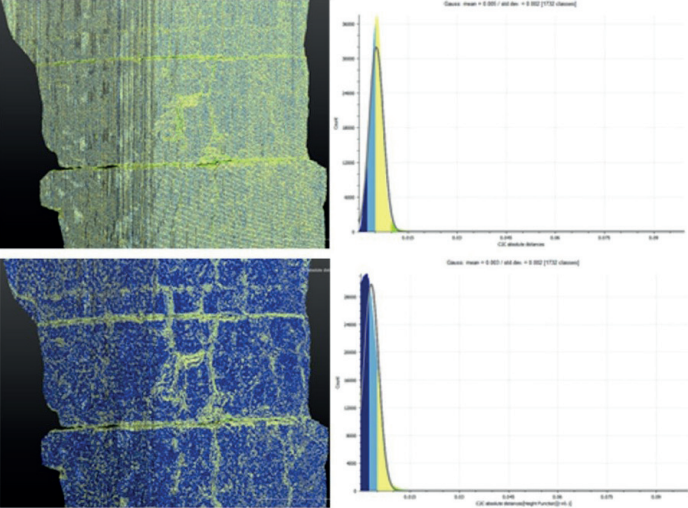

d)
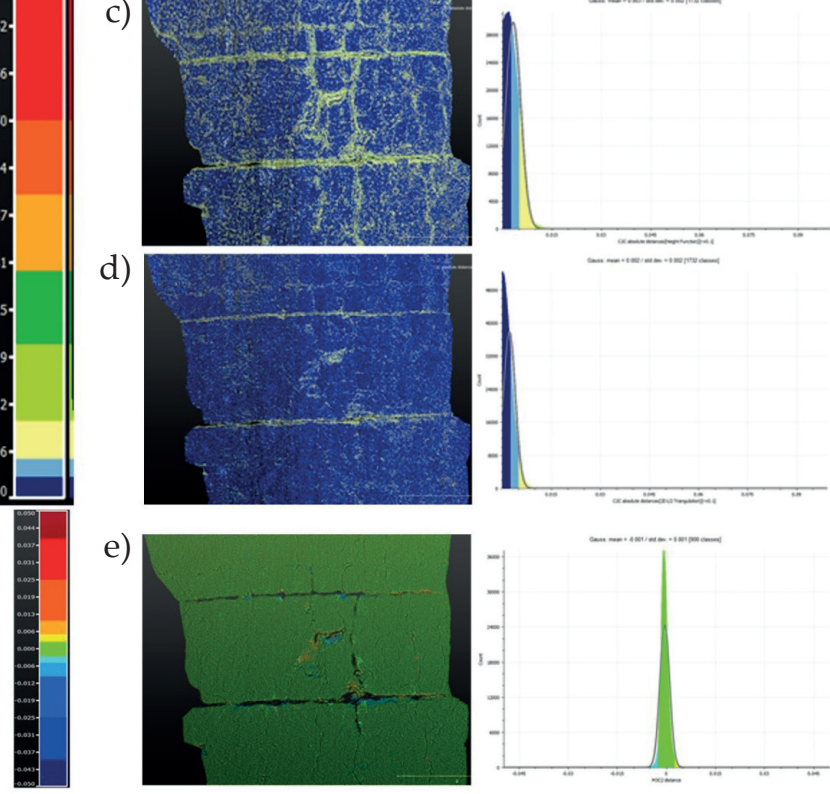

f)

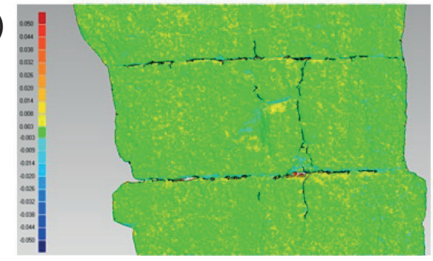

Fig. 1. Results of clouds comparison with different methods:

a) Original RGB; b) Nearest Neighbor; c) Height Function; d) 2.5D Delaunay Triangulation; e) M3C2; f) TIN model comparison 
a)

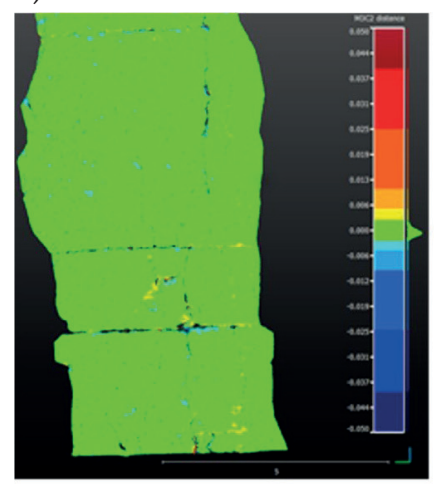

d)

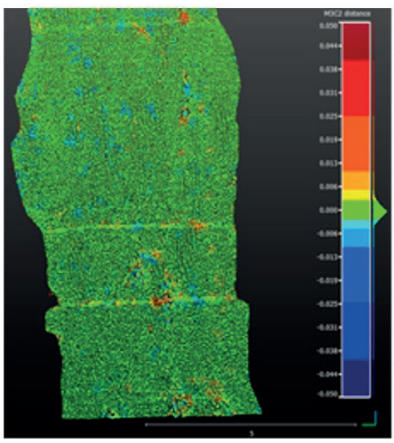

b)

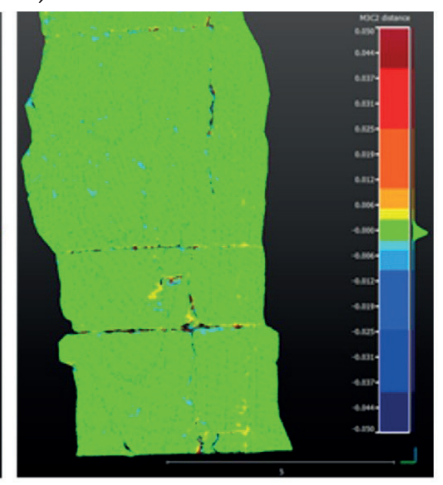

e) c)

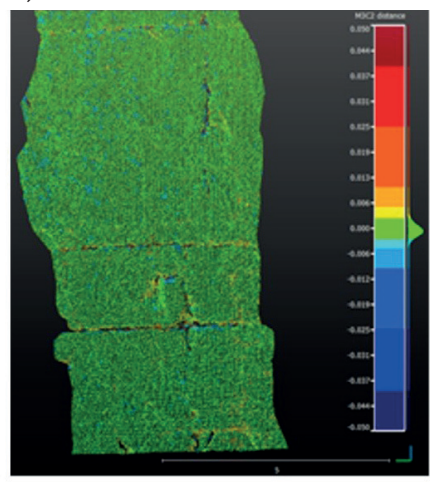

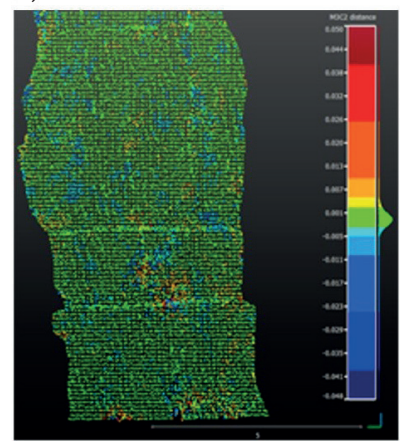

Fig. 2. Results of clouds comparison using points cloud of different density:

a) $5 \mathrm{~mm}$; b) $10 \mathrm{~mm}$;) $25 \mathrm{~mm}$; d) $50 \mathrm{~mm}$; e) $100 \mathrm{~mm}$

However, despite theoretical results at the level of $0 \pm 3 \mathrm{~mm}$ for $50 \mathrm{~mm}$ and $100 \mathrm{~mm}$ resolutions, it is visible that significant difference values, which do not correspond with actual displacements, appear in the places of the most varied structure. On the basis of this analysis, it was recognized that test objects of this type can be successfully measured with the resolution of up to $30 \mathrm{~mm}$.

\section{Calculating the Volume of Rock Cavities with Assessment of Accuracy}

After choosing an adequate method of point cloud comparison, the analysis of accuracy of marking the volume of emerging rock cavities was performed. Taking into account the fact that no cavities developed between subsequent sessions, third and fourth, calculating differences should be close to zero. The calculations were performed in Surfer 9 program by Golden Software company. GRID network was created by Natural Neighbor interpolation method with $2 \mathrm{~cm}$ step. Due to the fact 
that the algorithm of the program calculates the volumes along $\mathrm{Z}$ axis, it was necessary to transform the point clouds to make it maximally parallel to the plane created by $X$ and $Y$ axes. After creating GRID network for both measuring sessions, their range was limited to the area of examined object and then the volume between particular GRID networks was determined. Obtained results are presented in Table 3.

Table 3. Volumes of emerging rock cavities calculated for point clouds of different densities

\begin{tabular}{|c|c|c|c|c|c|c||}
\cline { 2 - 7 } \multicolumn{1}{|c|}{} & & & & & \multicolumn{2}{|c||}{ Relative error $\left[\frac{\mathrm{m}^{3}}{\mathrm{~m}^{2}}\right]$} \\
\hline \hline Original & 0.061 & 0.094 & -0.033 & 67.5 & 0.0009 & 0.0014 \\
\hline $10 \mathrm{~mm}$ & 0.064 & 0.091 & -0.027 & 67.5 & 0.0009 & 0.0013 \\
\hline $25 \mathrm{~mm}$ & 0.066 & 0.097 & -0.031 & 67.5 & 0.0010 & 0.0014 \\
\hline $50 \mathrm{~mm}$ & 0.088 & 0.132 & -0.044 & 67.5 & 0.0013 & 0.0020 \\
\hline $100 \mathrm{~mm}$ & 0.12 & 0.167 & -0.047 & 67.5 & 0.0018 & 0.0025 \\
\hline Avg. & 0.080 & 0.116 & -0.036 & - & \multicolumn{2}{c|}{0.0015} \\
\hline Std. dev & 0.022 & 0.029 & 0.008 & - & \multicolumn{2}{|c|}{0.0005} \\
\hline
\end{tabular}

Computed volumes for density ranges under $25 \mathrm{~mm}$ adopted the values of ca. $0.03 \mathrm{~m}^{3}$ and ca. $0.05 \mathrm{~m}^{3}$ for the clouds with the density of $50 \mathrm{~mm}$ and $100 \mathrm{~mm}$. Therefore, it was recognized that obtained volumes result merely from measurement and computing errors. On the basis of these calculations, it was possible to determine volume relative error which was identified as a quotient of obtained volumes and surface area of test object. After averaging all the results, the value of $0.0015 \pm 0.0005$ was obtained. Similar calculations were conducted for models created in Geomagic program. It provided the results in a range of $0.1-0.2 \mathrm{~m}^{3}$ which, comparing to earlier outcomes, is a far worse result. Therefore, the volumes of cavities of remaining objects were calculated in Surfer.

\section{Results}

After establishing all parameters of accuracy of conducted measurements for the test object, two remaining areas were examined. However, before comparing them, it was necessary to filter the point clouds from vegetation situated on the object in the first place. In order to obtain the best results, manual filtering was carried out in Leica Cyclone program. Subsequently, the comparison of distances between 
point clouds for object no. 2 was performed (Figs 3, 4). This comparison enables indication of significant cavities which developed between the first and the second measurement session and reach up to $50 \mathrm{~cm}$. Furthermore, a few smaller but significant cavities were detected between the third and the fourth session. No significant deformations were noticed between second and third session. It is worth pointing out that it is possible to observe single, minor cavities of even $1 \mathrm{~cm}$.

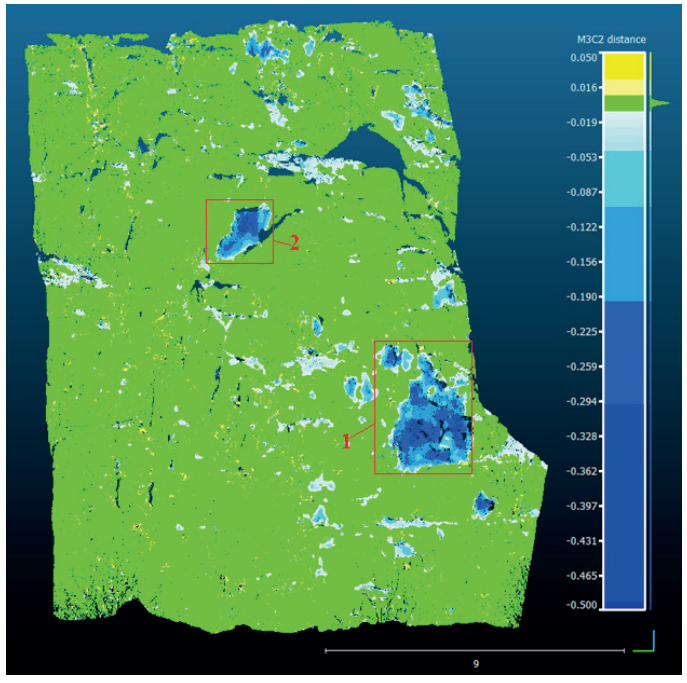

Fig. 3. Object no. 2 Comparison of the first and the second session

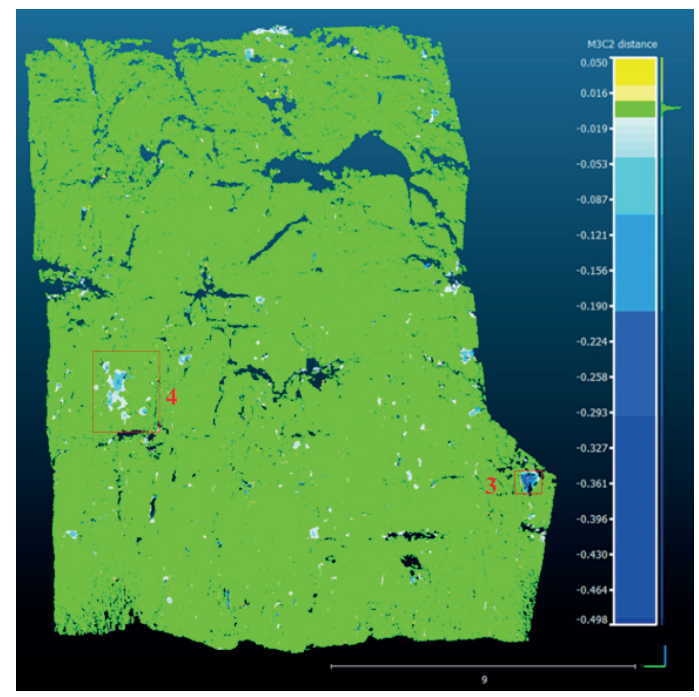

Fig. 4. Object no. 2 Comparison od the third and the fourth session 
Afterwards, the changes of volumes for the whole object and four areas with major changes were calculated. The calculations were performed for all combinations of measurement series. On the basis of positive volumes, which were considered to be caused by measurement errors and filtering, relative volume error and error limit value for significant changes were calculated.

These values were calculated as:

$$
S_{v}=\left(R_{e}+2.5 \cdot S_{d}\right) \cdot A,
$$

where:

$S_{v}$ - significant value $\left[\mathrm{m}^{3}\right]$,

$R_{e}$ - relative error $\left[\frac{\mathrm{m}^{3}}{\mathrm{~m}^{2}}\right]$,

$S_{d}-$ standard deviation calculated from all relative errors $\left[\frac{\mathrm{m}^{3}}{\mathrm{~m}^{2}}\right]$,
$A-$ calculated area $\left[\mathrm{m}^{2}\right]$.

Relative error value was assigned as quotient of positive volumes and surface area obtained for all compared areas and combinations of the compared session. Thus, a 30 values (five compared areas and six combination of compared session) for object no. 2 and 24 (four compared areas and six combination of compared session) for object no. 3 was determined. After that average value and it standard deviation was calculated and used to determine the limit error of significant error.

This provided the results presented in Table 4 .

Table 4. Volume results for object no. 2

\begin{tabular}{|c|c|c|c|c|c|c|c|c|c|c|}
\hline \multirow[b]{2}{*}{ 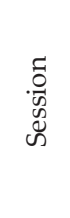 } & \multicolumn{2}{|c|}{ Whole object } & \multicolumn{2}{|c|}{ Area 1} & \multicolumn{2}{|c|}{ Area 2} & \multicolumn{2}{|c|}{ Area 3} & \multicolumn{2}{|c|}{ Area 4} \\
\hline & $\begin{array}{c}\Delta V \\
{\left[\mathrm{~m}^{3}\right]}\end{array}$ & $\begin{array}{c}\text { signif- } \\
\text { icant } \\
\text { value } \\
{\left[\mathrm{m}^{3}\right]}\end{array}$ & $\begin{array}{c}\Delta V \\
{\left[\mathrm{~m}^{3}\right]}\end{array}$ & $\begin{array}{c}\text { signif- } \\
\text { icant } \\
\text { value } \\
{\left[\mathrm{m}^{3}\right]}\end{array}$ & $\begin{array}{c}\Delta V \\
{\left[\mathrm{~m}^{3}\right]}\end{array}$ & $\begin{array}{l}\text { significant } \\
\text { value }\left[\mathrm{m}^{3}\right]\end{array}$ & $\begin{array}{c}\Delta V \\
{\left[\mathrm{~m}^{3}\right]}\end{array}$ & $\begin{array}{c}\text { signif- } \\
\text { icant } \\
\text { value } \\
{\left[\mathrm{m}^{3}\right]}\end{array}$ & $\begin{array}{c}\Delta V \\
{\left[\mathrm{~m}^{3}\right]}\end{array}$ & $\begin{array}{c}\text { signif- } \\
\text { icant } \\
\text { value } \\
{\left[\mathrm{m}^{3}\right]}\end{array}$ \\
\hline $2-1$ & -2.1864 & \multirow{3}{*}{ \pm 1.2529} & -1.0516 & \multirow{3}{*}{ \pm 0.0404} & -0.2502 & \multirow{3}{*}{ \pm 0.0126} & -0.0044 & 0.0065 & -0.0063 & \multirow{3}{*}{ \pm 0.0492} \\
\hline $3-2$ & 0.2311 & & -0.0022 & & -0.0007 & & 0.0013 & 0.0065 & 0.0062 & \\
\hline $4-3$ & -0.0605 & & -0.0029 & & 0.0015 & & -0.0398 & 0.0065 & -0.0239 & \\
\hline $\begin{array}{c}\text { Area } \\
{\left[\mathrm{m}^{2}\right]}\end{array}$ & \multicolumn{2}{|c|}{229.4} & \multicolumn{2}{|c|}{7.4} & \multicolumn{2}{|r|}{2.3} & \multicolumn{2}{|c|}{1.1} & \multicolumn{2}{|c|}{6} \\
\hline & & \multirow{2}{*}{\multicolumn{2}{|c|}{ Relative error }} & $\mathrm{m}^{3}$ & 0.0022 & \multicolumn{3}{|c|}{ Average value } & & \\
\hline & & & & & \pm 0.0013 & \multicolumn{3}{|c|}{ Standard deviation } & & \\
\hline
\end{tabular}


As can be seen, the measurement for the whole object is vitiated by relatively serious error of determining the volume, which stems from the large surface and irregular structure of the object. On the other hand, on the areas covered by the greatest changes, cavities amount up to $1 \mathrm{~m}^{3}$. Analyzing smaller areas where the cavities were detected, the error of determining the volume calculated according to proposed procedure is considerably smaller. Corresponding analysis was conducted for object no. 3. Here, as a result of comparing point clouds, substantial changes between the first and the second but also the third and the fourth session, when the cavities of values up to $60-70 \mathrm{~cm}$ developed, were detected. Volumes of these cavities reached the value of up to $2.2 \mathrm{~m}^{3}$. The results are shown in Figures 5 and 6 and Table 5 .

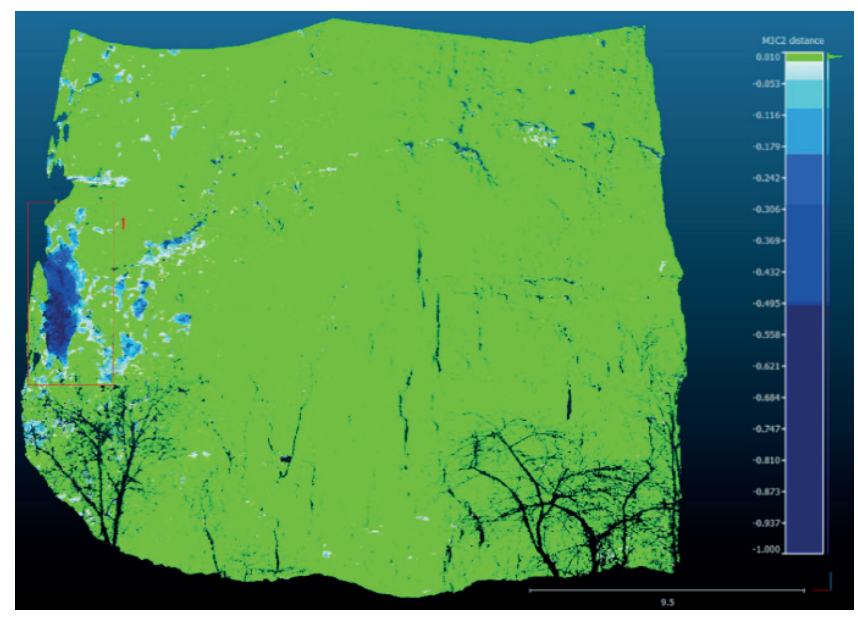

Fig. 5. Object no. 3. Comparison the first and the second session

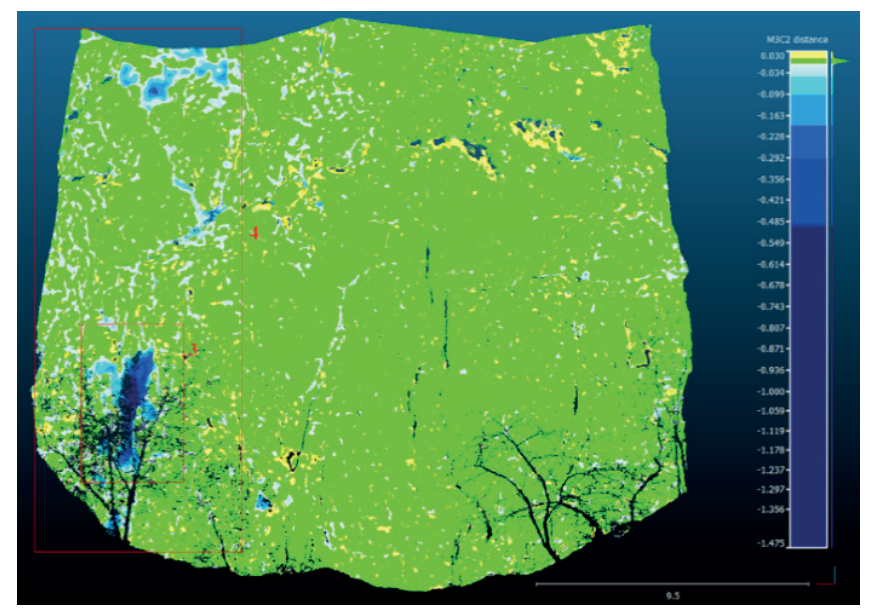

Fig. 6. Object no. 3. Comparison the first and the second session 
Table 5. Volume results for object no. 3

\begin{tabular}{|c|c|c|c|c|c|c|c|c|}
\hline \multirow[b]{2}{*}{ Session } & \multicolumn{2}{|c|}{ Whole object } & \multicolumn{2}{|c|}{ Area 1} & \multicolumn{2}{|c|}{ Area 2} & \multicolumn{2}{|c|}{ Area 3} \\
\hline & $\Delta V\left[\mathrm{~m}^{3}\right]$ & $\begin{array}{l}\text { significant } \\
\text { value }\left[\mathrm{m}^{3}\right]\end{array}$ & $\Delta V\left[\mathrm{~m}^{3}\right]$ & $\begin{array}{l}\text { significant } \\
\text { value }\left[\mathrm{m}^{3}\right]\end{array}$ & $\Delta V\left[\mathrm{~m}^{3}\right]$ & $\begin{array}{l}\text { significant } \\
\text { value }\left[\mathrm{m}^{3}\right]\end{array}$ & $\Delta V\left[\mathrm{~m}^{3}\right]$ & $\begin{array}{l}\text { significant } \\
\text { value }\left[\mathrm{m}^{3}\right]\end{array}$ \\
\hline $2-1$ & -2.1413 & \multirow{3}{*}{ \pm 3.5618} & -1.7520 & \multirow{3}{*}{ \pm 0.0826} & -2.2189 & \multirow{3}{*}{ \pm 0.4917} & -0.3682 & \multirow{3}{*}{ \pm 0.2097} \\
\hline $3-2$ & 0.1737 & & -0.0040 & & 0.0284 & & 0.0069 & \\
\hline $4-3$ & -2.6391 & & -0.0601 & & -1.7256 & & -1.4756 & \\
\hline \multirow[t]{3}{*}{$\begin{array}{l}\text { Area } \\
{\left[\mathrm{m}^{2}\right]}\end{array}$} & \multicolumn{2}{|r|}{383.9} & \multicolumn{2}{|r|}{8.9} & & 53 & \multicolumn{2}{|c|}{22.6} \\
\hline & \multirow{2}{*}{\multicolumn{3}{|c|}{ Relative error [] }} & 0.0040 & \multicolumn{3}{|c|}{ Average $\left[\mathrm{m}^{3} / \mathrm{m}^{2}\right]$} & \\
\hline & & & & \pm 0.0021 & \multicolumn{3}{|c|}{ Standard deviation $\left[\mathrm{m}^{3} / \mathrm{m}^{2}\right]$} & \\
\hline
\end{tabular}

\section{Conclusions}

On the basis of obtained results, laser scanning method may be considered as highly useful for measuring the volume and deformations of rock cavities. It allows for marking deformations even with a few millimeters accuracy and, at the same time, provides the full image of developed changes. However, it has to be noted that in order to obtain reliable results, the maximum reproducibility of conducted measurements and adequate method of point cloud comparison has to be adopted. At the same time, it is possible to precisely define the volume of remaining cavities. In this case, the best solution is to carry out the measurements only for the areas where the cavities were previously identified.

\section{References}

[1] Zagrożenia naturalne w odkrywkowych zakładach górniczych. Wyższy Urząd Górniczy, Katowice 2007.

[2] Girard J.M.: Assessing and monitoring open pit mine highwalls. [in:] Proceedings of the 32nd Annual Institute on Mining Health, Safety and Research, Salt Lake City, Utah, August 5-7, 2001, University of Utah, Salt Lake City 2001, pp. 159-171.

[3] Hearn G.J.: Slope Engineering for Mountain Roads. Geological Society Engineering Geology Special Publication, vol. 24, Geological Society of London, London 2001. 
[4] Olek B., Woźniak H., Stanisz J.: Statistical methods used for determining geotechnical parameters. Przegląd Geologiczny, r. 62, nr 10/2, 2014, pp. 657-663.

[5] Motyka J., Czop M.: Vertical Changes of Iron and Manganese Concentration in Water from Abandoned "Zakrzówek" Limestone Quarry near Cracow (South Poland). [in:] Mine water and the environment: proceedings of the 10th IMWA congress 2008: 2-5 June, 2008, Karlovy Vary, Czech Republic, VSB - Technical University of Ostrava, Ostrava, pp. 167-170.

[6] Alba M., Fregonese L., Prandi F., Scaioni M., Valgoi P.: Structural Monitoring of Large Dam by Terrestrial Laser Scanning. [in:] Proceedings of the ISPRS Commission V Symposium "Image Engineering and Vision Metrology": Remote Sensing and Spatial Information Sciences, vol. 36, part 5, pp. 1-6, September 25-27, 2006 Dresden, Germany.

[7] Lague D., Brodu N., Leroux J.: Accurate 3D comparison of complex topography with terrestrial laser scanner: application to the Rangitikei canyon (N-Z). ISPRS Journal of Photogrammetry and Remote Sensing, vol. 82, 2013, pp. 10-26.

[8] CloudCompare v2.6.1 Documentation.

[9] Girardeau-Montaut D., Roux M., Marc R., Thibault G.: Change detection on points cloud data acquired with a ground laser scanner. [in:] ISPRS Workshop Laser Scanning 2005: Enschede, the Netherlands, 12-14 September 2005, GITC, pp. 30-35. 